\title{
AVALIAÇÃO E QUALIDADE DO DESENVOLVIMENTO PROFISSIONAL DOCENTE
}

\author{
Bernardete Angelina Gatti*
}

Recebido: 5 mar. $2014 \quad$ Aprovado: 30 maio 2014

*Pesquisadora Fundação Carlos Chagas, São Paulo, SP, Brasil. Contato com a autora: gatti@fcc.org.br

Resumo: $\mathrm{O}$ artigo trata de três questões básicas: qual perspectiva avaliativa se assume ao desenvolver uma avaliação de natureza educacional, o que se está entendendo por qualidade, e, qual o significado atribuído a desenvolvimento profissional. Levanta perspectivas diferentes em processos avaliativos, o que determina atitudes e impactos, levanta o problema e os dilemas na conceituação do que seja qualidade docente, lembrando que o trabalho docente é diferenciado de outros focos de trabalho uma vez que envolve um alto grau de subjetividade. Por fim, aborda a questão do desenvolvimento profissional, assumindo a perspectiva de evoluções/revoluções nos diferentes ciclos da vida de um profissional docente, no âmbito do desenvolvimento humano adulto, associado a espaços de trabalho. Trata, então de algumas formas avaliativas utilizadas e finaliza lembrando que o modo de iniciar e implementar processos avaliativos colocam exigências formativas e de posturas para os avaliadores e os avaliados.

Palavras-chave: Avaliação. Avaliação de docentes. Qualidade profissional. Desenvolvimento profissional. Propostas de avaliação.

\section{EVALUATION, QUALITY AND TEACHER PROFESSIONAL DEVELOPMENT}

Abstract: The paper discusses three basic questions: Which evaluative perspective do we take when carrying out an educational evaluation? What do we mean by quality? and What do we mean by professional development? It raises different perspectives in the evaluative processes, which determine attitudes and impacts, raises the problem and the dilemmas with regard to defining teacher quality, remembering that a teacher's work is different from other activities since it involves a high degree of subjectivity. Furthermore, the paper approaches the issue of professional development, taking the perspective of evolutions/revolutions in the different life cycles of a teacher, in the realm of adult human development, associated with his working space. It deals, then, with some current evaluative forms and ends up reminding that the way of initiating and implementing evaluative processes places formative and attitudinal demands on evaluators and evaluatees.

Key words: Evaluation. Teacher evaluation. Professional quality. Professional development. Evaluations models. 
Três questões se colocam, de início, quanto ao tema: qual perspectiva avaliativa se assume, o que se está entendendo por qualidade, e, qual o significado atribuído a desenvolvimento profissional. Procuraremos abordar brevemente cada uma dessas questões na intenção de oferecer um cenário, como pano de fundo, para posturas relativas à avaliação do trabalho docente e sua associação com desenvolvimento profissional.

\section{AVALIAÇÃO E QUALIDADE}

Quanto às perspectivas sobre avaliação, devemos lembrar que avaliações não são neutras e quando se trata de associá-las a políticas públicas, a perspectiva filosófica que se enraíza em sua forma de concepção, suas finalidades, objetivos, procedimentos, bem como os comportamentos e atitudes de gestores e avaliadores, determinam seus consequentes e evidenciam o papel institucional, social e/ou educacional a elas atribuídos, ou seja, a que ideário se vincula e o que delas se espera. Podemos, grosso modo, coloca-las em dois grandes grupos: os processos avaliativos que carregam em seu fazer uma perspectiva unicamente funcionalista-pragmatista e os que portam em suas formas de implementação uma perspectiva dinâmica, analítico-construtiva ou de reflexão radical ${ }^{1}$.

Os processos avaliativos que podem ser agregados ao primeiro grupo citado, em geral, resumem-se a modelos somativos, com base em pontuações que traduzem o alcance, ou não, de certos critérios ou metas. No mais das vezes essa modalidade avaliativa tem caráter externo sendo realizada por especialistas. Referindo-se à docência, a partir dos dados obtidos, pode ou não associar-se à progressão na carreira ou a processos de formação continuada. Muitas vezes os resultados desse tipo de avaliação são colocados como indicadores ou sinalizadores de uma dada situação. Uma variação dentro desses modelos é a utilização do desempenho de alunos em avaliações externas de sistema como indicador do desempenho docente. A ideia subjacente é que, com as pontuações ou desempenhos obtidos e divulgados é possível desencadear por parte dos avaliados a busca por meios para melhorar essas pontuações ou desempenhos, o que redundaria em desenvolvimento profissional docente, ou institucional no caso dessa avaliação se referir a um coletivo. Os modelos neste grupo apoiam-se em categorizações ou escalas utilizadas por avaliadores externos ao grupo profissional.

1 Na expressão de Saviani e Duarte (2012, p. 15) uma reflexão radical, rigorosa e de conjunto sobre problemas da realidade responde à tarefa de vigilância crítica do pensamento humano sobre a realidade social e histórica. 
Os processos avaliativos postos no segundo grupo, mostram-se com foco explícito na valorização e desenvolvimento das pessoas, grupos ou instituições, e esse desenvolvimento, associado a processo de valorização profissional, é que se constitui no cerne metodológico da avaliação e de seus procedimentos. Mostram-se com metodologias de caráter formativo, com envolvimento direto dos participantes. São metodologias que visam dinamizar processos de aprendizagem sociocognitiva, utilizando processos formativos dinâmicos, interpessoais, grupais, societários. Esses processos são meios de alavancar pessoas e ações, ajudar a superar problemas e impasses, no próprio processo de avaliação em seu curso - trazer à tona realidades e lidar com elas. Isso implica a participação direta dos avaliados, como pessoas e profissionais, ou como um coletivo de trabalho em dada instituição. Pressupõem colocar em evidência suas premissas formativas, os valores e contextos de referência em relação aos quais se avalia, compartilhando-os. É processo que visa a compreensão, por reflexão compartilhada, de fatores que sustentam determinados tipos de ação, atitudes, valores, e o sentido dos mesmos em um dado contexto. Tem por objetivo propiciar reflexões institucionais na direção de constituir/reconstituir valores socioculturais, desvendar processos tidos como colaterais, mas que não o são, por exemplo, o das competências sociais, ou das contribuições para melhor qualidade de vida e trabalho, para processos de compartilhamento de formas vivenciais coletivas, ou de buscas coletivas de superação de situações consideradas problemáticas, entre outros aspectos possíveis. Modelos deste grupo encontram respaldo nas propostas de Saul $(1988 ; 2007)$ e de Subirats (1993, p. 256) processo de aprendizagem contínuo, em serviço, o que implica manter "um perfil participativo e de incorporação de critérios plurais na consideração dos fatores a serem tomados em conta".

Os modelos avaliativos propostos na literatura especializada para a avaliação de docentes podem se encaixar em uma ou outra dessas perspectivas. Ambas, em última instância, visam propiciar algum tipo de desenvolvimento profissional, pelo desvelamento de impasses ou problemas, e, de construção de alternativas de superação dos impasses, de forma a permitir avanços formativos que contribuam para uma qualificação cada vez maior e mais atualizada do profissional docente. O que as diferencia radicalmente é a perspectiva com a qual são desenvolvidas, como acima colocamos: a partir de indicadores externos, em geral quantitativos ou categóricos, ou, a partir do envolvimento participativo, reflexivo, pessoal, dos profissionais. É preciso considerar que as duas perspectivas assinaladas, através de seus métodos e dos meios a eles associados, podem combinar-se, como um modelo híbrido portador de algumas características de um e de outro 
grupo. Exemplo desse modelo é o apresentado por Danielson $(2010 ; 2013)$ sobre o qual teceremos pequena consideração adiante.

Quanto ao significado atribuído ao termo qualidade, a pergunta recorrente que aparece ao se discutir processos avaliativos de professores é: como evidenciar qualidade docente? Para isto precisamos de uma perspectiva de fundo, clara e compartilhada. Não dá para partir do pressuposto que a mesma ideia de qualidade, com seus componentes, esteja claramente posta para gestores, equipes escolares, ou o universo das redes de ensino e das instituições formadores de educadores. O sentido de qualidade precisa ser tornado transparente, ou por uma conceituação externa clara, ou pela sua construção por um coletivo em consenso. Aí se saberá o que se está entendendo por qualidade. Apenas para exemplificar, e reduzindo o conceito, pode-se esclarecer em dada situação, que o termo está associado a bom comportamento (assíduo, obediente, etc.), ou a competências cognitivas (conhecimento dos conteúdos de uma área disciplinar, cultura geral, etc.), ou a simpatia, ou a beleza, etc.. O que queremos pontuar é que, numa visão democrática, a avaliação do trabalho docente, sendo intencional e sistemática, pressupõe colocar em evidência algumas premissas sobre esse trabalho, suas finalidades, em determinado contexto, os valores em relação aos quais se avalia. Constitui-se, assim, como um processo de investigação de uma realidade profissional no campo educacional em que vários aspectos se entrecruzam, numa certa maneira de entender qualidade social e educacional, a qual deve estar esclarecida em suas características e critérios - formulados a priori ou construídos em um processo de troca coletivo, e, em ambos os casos, tomados como ponto de partida para a ação avaliativa. Transparência de premissas e critérios é essencial.

Com experiência em vários setores de trabalho, contemporaneamente alguns autores assumem a posição de que um processo avaliativo de profissionais (e aqui pensamos em professores) necessita assumir uma natureza mais qualitativa, menos numérica, e que deve que se iniciar na situação efetiva de trabalho, no nosso caso, na escola, por trocas coletivas e reflexões que permitam fazer emergir com clareza uma perspectiva minimamente com algum consenso (CARVALHO, 1999; AFONSO, 2005; CANÁRIO, 2007; SANTOS, 2009). Esta maneira, em dada escola, pode combinar aspectos próprios às suas condições e contexto local, conjugados com aspectos mais amplos da finalidade das escolas e do trabalho docente em uma rede, numa determinada sociedade. Assim, está colocada a questão de qualificar de que tipo de qualidade está-se falando, e quem está decidindo o que compõe essa qualidade, que é uma das questões básicas a enfrentar nesses processos. 
As categorias referenciais em geral encontradas em modelos de avaliação de professores quanto ao trabalho na docência, nem sempre são suficientes em si, porque nota-se neles a falta de explicitação no que se refere à sua contextualização, a certas nuances necessárias, às adequações e maior detalhamento relativo a aspectos específicos, considerando-se: a) realidades locais específicas para o exercício da docência, b) a própria formação dos docentes e avaliadores, e, c) a cultura regional/local. Nem por isso são desprezíveis, uma vez que podem ser tomados como ponto de apoio para esses processos, em suas diferentes perspectivas e em diferentes cenários.

Então, a questão da avaliação da qualidade docente não se situa apenas em se ter um esquema conceitual, portanto racional genérico, adequado aos objetivos e ao campo institucional definido para a avaliação, mas, sobretudo no modo como se concebe, como se conceitua essa qualidade - no caso, por exemplo, o que se entende por ensino, por finalidade da escola, seu papel local e social, por qualidade institucional, por qualidade de ensino e de aprendizagem - o que permitiria enunciar critérios de qualidade que sejam adequados a uma dada realidade educacional. Ou seja, critérios que não sejam abstratos, descolados do agir educativo em dadas condições, nem reducionistas que se exprimam somente por categorias estreitas, uma nota ou uma pontuação em uma escala sem conotações significantes para os participantes do processo avaliativo. Sem ter sentidos concretos para estes, as avaliações caem num vazio, não mobilizam e não geram consequências positivas.

Estas questões são importantes quando se trata de avaliação do trabalho docente porque este, como afirmam Ferreira e Hypólito (2010), caracteriza-se como um trabalho diferenciado de outros na medida em que envolve um alto grau de subjetividade e, em relação a ele, não se tem uma medida absoluta daquilo em que resulta. Vários analistas do trabalho docente, de fato, apontam para a complexidade atual do papel do educador escolar que implica não só domínio de conhecimentos disciplinares e metodologias de ensino, como também compreensões sobre o desenvolvimento das crianças e jovens, cognitivo, afetivo, social, compreensão e capacidade de lidar com diferenças (por exemplo, a heterogeneidade dos alunos), habilidade de comunicação e didática, bem como de geração de motivação para o conhecimento. Isto, em um ambiente de escola e sala de aula, perpassado por questões culturais, por políticas educacionais de governos, pelas informações midiáticas, ambiente ainda perpassado por processos relacionais-afetivos, pela vivência e convivência com situações as mais variadas, pelas necessidades comunitárias e pessoais de todos os atores envolvidos. (TARDIF, 2003; MELO, 2008; LOURENCETTI, 2008; GATTI; BARRETTO; ANDRÉ, 2011). 


\section{DESENVOLVIMENTO PROFISSIONAL}

Com as considerações anteriores adentramos na discussão sobre desenvolvimento profissional de professores, que, acreditamos, é questão que necessita ser colocada e considerada de maneira um pouco diversa em relação a outras categorias de trabalhadores. Esse desenvolvimento não pode ser confundido com aspectos de um plano de carreira, ou a ele reduzido, embora possa com ele ter associações e intersecções. Também não pode ser identificado apenas como competência profissional, onde competência se alia a eficiência. Integra-se, sobretudo, com a ideia de evoluções/revoluções nos diferentes ciclos da vida de um profissional docente, em perspectivas de desenvolvimento humano adulto, associado ao desenvolvimento profissional. Considerando a inter-relação entre um processo de avaliação com vistas à qualidade do desenvolvimento profissional de docentes, temos que ter em conta que esse processo visa alterar condições pessoais/profissionais para melhor. Para tanto, são necessárias ações conscientes, baseadas em uma reflexão mais objetiva sobre a realidade experimentada, vivenciada, reflexão que impulsionará atitudes e ações inovadoras, que se traduzam em práticas efetivas de mudança. Isso só se efetivará com um esforço de superação de nossa condição de rotina na vida cotidiana, na busca constante de entender com clareza as situações em que vivemos e trabalhamos, para mudarmos, avançarmos em relação à situação atual. Um processo avaliativo voltado ao desenvolvimento humano-profissional pode ter encaminhamento nessa direção. $\mathrm{O}$ desenvolvimento profissional alia-se a se ter uma visão mais clara do que impede movimentos de transformação de si ou de uma realidade, no caso de nossa realidade educacional próxima, nas escolas, e nas redes educacionais, no ensino e em sua gestão. Considerado nesta perspectiva, um processo de avaliação do trabalho docente, na sua inserção institucional, pode ser um meio para a tomada de consciência de determinadas situações pedagógico-didáticas, que permita construir superação de condições na direção da reconstrução constante da profissionalidade ${ }^{2}$ docente, das ações pedagógicas, dos aprendizados dos estudantes, em relação e decorrência de um processo desencadeado nessa direção. Na perspectiva acima colocada é que concebemos o desenvolvimento profissional. Em outro trabalho, defendemos que a avaliação do trabalho docente é relevante apenas quando esta avaliação é concebida e realizada com propósitos de valorização desse trabalho, de oferecer elementos para o desenvolvimento profissional de professores na direção de

2 Profissionalidade é aqui entendida como a condição que revela a construção de uma base sólida de conhecimentos e formas de ação em dada área de trabalho. 
um avanço contínuo em suas condições profissionais. Sobretudo, de propiciar a construção de novas competências no movimento do complexo contexto da educação escolar e dos movimentos societários-culturais, onde aspectos comunitários internos e externos à escola, aspectos das culturas dos estudantes que sucessivamente chegam a ela, se modificam no tempo. Esse movimento avaliativo tem que ser do interesse dos próprios professores em busca da construção de uma condição de profissionalidade não fossilizada. Constitui-se na perspectiva de oferecer elementos para atualização constante, crescimento pessoal, profissional e de uma dada coletividade escolar (GATTI, 2013, p. 143).

\section{FORMAS AVALIATIVAS PROPOSTAS E DESENVOLVIMENTO PROFISSIONAL}

As formas que encontramos sendo empregadas para a avaliação de docentes são diversas, podendo ir desde medidas dos conhecimentos dos professores em sua área de atuação e/ou na área pedagógica, em determinados momentos da carreira, até a avaliação por experts no local de trabalho, em formas participativas ou não, a avaliação por chefias ou por pares, ou auto-avaliação. Os fatores incorporados nessas avaliações podem ser de diversos tipos, como, assiduidade, comprometimento, capacidade de iniciativa e inovação, aperfeiçoamento constante em conhecimentos, ação didática consistente, aperfeiçoamento nos conhecimentos da área e afins, entre outros. Há propostas para essa avaliação que utilizam os desempenhos dos alunos como dado que evidencia a qualidade da atuação do professor, sendo estes modelos bastante usuais. Há críticas a todos esses tipos de avaliação, seja por serem passíveis de ser afetados pela subjetividade dos avaliadores, seja porque traduzem em números aspectos qualitativos de modo arbitrário, seja por outros fatores relevantes. Mais recentemente observa-se intensificação de críticas aos processos de avaliação do trabalho docente que se apoiam na performance do professor a partir do desempenho de seus alunos (ODDENAN; KELLEY, 1996; AFONSO, 2005; HANUSHEK et al., 2005; CASSETARI, 2010). Os problemas apontados são muitos, como o fato de não se considerar todos os fatores intervenientes nesse desempenho, ou a fragilidade dos modelos estatísticos utilizados para essa associação, etc. (a respeito ver SILVA; MORICONE; GIMENES, 2013, p. 71-108).

Nem todas as formas acima citadas contribuem, de fato, para o desenvolvimento profissional docente, na concepção que acima expusemos. Danielson (2010; 2013), entre outros autores, discute questões relativas às novas tendências em avaliação de professores destacando os processos avaliativos que têm 
como característica principal o de serem desenvolvidos na própria escola, no ambiente de atividades do professor, na interação com este, com observações, acompanhamento de atividades, e outros meios como portfólios, diálogos, o que nos leva a pensar uma avaliação de caráter ad-hoc e não uma avaliação de massa, despersonalizada e descontextualizada. Por outro lado, essa autora também considera importante que é preciso garantir maior validade ao processo, e para isso propõe um conjunto de aspectos a serem considerados em um sistema avaliativo compreensivo, baseando-se em categorias que pretendem oferecer certo rigor e possibilidade de comparabilidade, porém com flexibilidade, nesse processo. A elaboração de categorias avaliativas, nesta proposta, é voltada a aspectos qualitativos, porém, passível de ser traduzida em formas válidas e comparáveis de interpretação, através de critérios claros e compartilhados. A ideia no modelo que propõe é tentar contornar as críticas de excesso de subjetividade de avaliadores ao avaliarem docentes apenas a partir de observações e entrevistas abertas. No modelo proposto, acrescente-se a abertura da possibilidade de coparticipação ativa do professor nesse processo, seja na preparação para o mesmo, e/ou no período de seu desenvolvimento e/ou posteriormente ao seu término, como uma atividade de reflexão quanto aos elementos evidenciados no desenvolvimento da avaliação, para possíveis reposicionamentos. Com isso, a contribuição visada é para a formação contínua dos docentes, pelos feedbacks do processo avaliativo, sua discussão com reflexão crítica, visando tomadas de decisão com delineamentos para melhor qualificação de caminhos profissionais. Danielson (2010) também aponta para a necessária formação do avaliador, sua capacitação interativa, aspecto importante para a relação deste com os profissionais a serem avaliados.

O modelo apresentado por Danielson (2010) é uma proposta de avaliação de professores em situação - nas escolas, por constatações por diferentes meios, na direção primeira de prover elementos para a melhoria da qualidade de atuação dos professores, em interface direta. É proposta para ser realizada em espaços bem delimitados, que deve ser feita em um tempo mais extenso, pois demanda acompanhar o dia a dia do professor, alcançar aspectos de sua relação com a comunidade de abrangência da escola, com as famílias, etc.

Com essas características, não é, pois, trivial pensá-la para uma rede de ensino de grande porte. Mas, não é inviável, especialmente se centrada na escola ou subconjuntos de escolas, visando melhorias da ação docente em nichos específicos.

Muitas propostas existem, mas, não cabe nos estender mais sobre elas aqui. Apenas destacamos que quando se trata de valorização profissional docente, 
os processos avaliativos do trabalho docente em perspectiva de avaliação institucional, com características de uma avaliação participativa-emancipatória, tomam relevância, como apresentado por Gatti (2013, p. 139-160).

\section{O NECESSÁRIO}

Sinteticamente, para o desenvolvimento de avaliações de professores em situação, de forma interativa, participativa, e visando o crescimento profissional e pessoal de professores seria necessário:

1) Preparação adequada nos sistemas, nos diferentes níveis gestores, nas escolas e suas equipes. Criar um clima não persecutório e de fundo punitivo, mas sim, uma cultura de crescimento profissional continuado.

2) Formação de lideranças expressivas que possam dar ao processo um sentido adequado, não ameaçador, mas sim, pedagógico.

3) Criação de um clima de sinceridade.

4) Formação dos avaliadores, tanto em conhecimentos sobre avaliação e seus meios e processos, seus limites e percalços, como em competência para criar afinidades e clima compreensivo.

5) Propiciar a criação de clima de abertura para aspectos problemáticos.

6) Criar condições para se saber lidar com o sucesso e os percalços.

7) Criar condições para que o processo avaliativo seja assumido como próprio, independente de pressão externa excessiva.

8) Criar condições para que ações sejam desenvolvidas, a partir do processo avaliativo, na direção de prover melhorias evidenciadas como importantes para a vida profissional do professor.

9) Levar em conta diferenças locais, regionais, culturais.

10) Garantir a continuidade dos processos avaliativos, em ciclos, ou etapas, e o suporte para iniciativas formativas decorrentes de inferências a partir da avaliação procedida.

11) Nunca deixar o processo avaliativo sem sequência de apoios e suporte às mudanças de consenso entre os participantes.

\section{FINALIZANDO}

Os aspectos aqui levantados colocam questões sobre o modo de iniciar e implementar processos avaliativos e colocam exigências formativas e de posturas para os avaliadores e os avaliados. Os processos avaliativos requerem atitudes 
consistentes, adequadas, e o desenvolvimento de atividades formativas relativas a eles. Processos avaliativos educativos demandam, também, a formação dos avaliadores para um relacionamento mais efetivo em relação aos professores, na perspectiva de motivação e desenvolvimento profissional, considerando sua valorização. Sempre presente deve estar a ideia de valorização profissional, por visar avanços em características da profissionalidade docente. Um processo avaliativo nesta perspectiva não pode alimentar negativismos. Também é necessário que esse processo faça parte do trabalho nas escolas, integrado a processos de formação continuada em serviço.

O clareamento de finalidades e perspectivas entre avaliadores e avaliados é aspecto essencial, bem como a existência de uma interface sociocultural entre ambos - aspecto nem sempre lembrado. A proposta avaliativa que implica perspectivas de consenso, diálogo e trocas, e que carrega a ideia de melhoria, de contribuição ao desenvolvimento pessoal e profissional, de agregar valor ao trabalho do professor, e não a ideia de seletividade e ranqueamento, de punitividade e negatividade, carrega um propósito humanista transformador. Portanto, carrega a ideia de contribuir para processos de mudança em direções relevantes. Avaliar para mudar, para melhorar sempre.

\section{REFERÊNCIAS}

AFONSO, A. J. Avaliação educacional: regulação e emancipação. São Paulo: Cortez, 2005.

CANÁRIO, R. Relatório geral. Formação e desenvolvimento profissional de professores. In: COMUNICAÇÃO apresentada no Painel: Aprendizagem ao longo da vida e desenvolvimento profissional de professores. Lisboa, Portugal: Ministério da Educação, 2007.

CARVALHO, M.C.B. de. Avaliação participativa - uma escolha metodológica. In: RICO, E. M. (Org.). Avaliação de políticas sociais. 2. ed. São Paulo: IEE-PUC-SP, 1999. p. 87-94.

CASSETARI, N. Remuneração variável para professores: revisão da literatura e desdobramentos no Estado de São Paulo. Dissertação (Mestrado em Educação) - Programa de Educação da Faculdade de Educação da USP, São Paulo, 2010. 
DANIELSON, C. New trends in teacher evaluation. SEMINÁRIO AVALIAÇÃO DE PROFESSORES DA EDUCAÇÃO BÁSICA: UMA AGENDA EM DISCUSSÃO. Cesgranrio: Rio de Janeiro, 24 de maio de 2010. Texto-referência de Mesa Redonda - Avaliação de Professores: um modelo em discussão.

. The framework for teaching: evaluation instrument. Princeton: The Danielson Group, 2013.

FERREIRA, L. S.; HYPOLITO, A. M. De qual trabalho se fala?

Movimentos de sentidos sobre a natureza, processos e condições de trabalho dos professores. In: SEMINÁRIO DA REDE LATINO-AMERICANA DE ESTUDOS SOBRE TRABALHO DOCENTE - REDE ESTRADO, 8., 2010, Lima. Anais... Lima: Rede Estrado, 2010. 1 CD-ROM.

GATTI, B. A. (Org.). O trabalho docente: avaliação, valorização, controvérsias. Campinas: Autores Associados, 2013.

GATTI, B.A.; BARRETTO, E.S.S.; ANDRÉ, M.E.D.A. Políticas docentes no Brasil: um estado da arte. Brasília: UNESCO, 2011.

HANUSHEK, E. et al. The market for quality teachers. National Bureau of Economic Research Working Paper Series, 2005. Disponível em: $<$ http:// www.nber.org/papers/w11154, pdf/new_window=1>. Acesso em: 19 fev. 2010 .

LOURENCETTI, G. C. O trabalho docente dos professores secundários na atualidade: intersecções, particularidades e perspectivas. Araraquara (SP): Junqueira \& Marin, 2008.

MELO, S. D. G. Trabalho e conflituosidade docente: alguns aportes. In: SEMINÁRIO DA REDE LATINO-AMERICANA DE ESTUDOS SOBRE TRABALHO DOCENTE-REDE ESTRADO, 7., 2008, Buenos Aires. Anais... Buenos Aires: Rede Estrado, 2008. 1 CD-ROM.

ODDEN, A.; KELLEY, C. Paying teacher for what they know and do: new and smarter compensation strategies to improve schools. Thousand Oaks: Cowin Press, 1996.

SANTOS, A.A. dos. Avaliação de professores em Portugal: modelos e perspectivas. In: RUIVO, J.; TRIGUEIROS, A. (Coord.). Avaliação de 
desempenho de professores, Portugal, Lisbos: RVJedit; Associação Nacional de Professores, 2009. p. 13-24.

SAUL, A. M. Avaliação emancipatória: desafio à teoria e à prática de avaliação e reformulação de currículo. São Paulo: Autores Associados; Cortez, 1988.

. Avaliação participante - uma abordagem crítico-transformadora. In: RICO, E. M. (Org.). Avaliação de políticas sociais: uma questão em debate. São Paulo: Cortez; IEE/PUCSP, 2007. p. 95-109.

SAVIANI, D.; DUARTE, N. Pedagogia histórico-crítica e luta de classes na educação escolar. Campinas: Autores Associados, 2012.

SILVA, V. G.; MORICONI, G. M.; GIMENES, N.A.S. Uso de resultados dos alunos em testes padronizados na avaliação docente: esclarecendo o debate. In: GATTI, B.A. (Org.). O trabalho docente: avaliação, valorização, controvérsias. Campinas: Autores Associados, 2013. p. 71 - 108.

SUBIRATS, J. Evaluación de políticas de intervención social. Un enfoque pluralista. In: INTERCAMBIO SOCIAL Y DESARROLLO DEL BIEN ESTAR. CSIC, Madrid, 1993.

TARDIF, M. Saberes docentes e formação profissional. 3. ed. Petrópolis: Vozes, 2003. 